\title{
Os Baniwa e a escola: sentidos e repercussões
}

\section{Valéria Augusta Cerqueira de Medeiros Weigel}

Universidade Federal do Amazonas, Programa de Pós-Graduação em Educação

\section{Da problemática e seu estudo}

Por que um povo indígena se mobiliza e empreende lutas por escola? Quais sentidos e repercussões a educação escolar tem tido para o povo Baniwa? Esse povo é habitante milenar da bacia do rio Içana, afluente da margem direita do rio Negro, no noroeste do estado do Amazonas.

Essas perguntas motivaram a realização de estudos sobre a escola na área Baniwa. Neste texto apresento alguns resultados políticos e socioculturais desses estudos, mostrando os Baniwa em suas relações com os outros atores sociais existentes na região do Alto Rio Negro, especificando as relações concernentes à produção de diferentes formas de educação escolar (em sua essência, significados e repercussões), ligadas a diferentes interesses e sentidos, representações de mundo e projetos políticos.

Estudos recentes revelam um processo acelerado de transformação das culturas orais na região do Alto Rio Negro (Oliveira, 1981, 1992; Ribeiro, 1970; Wright, 1981, 1994, entre outros). Tal processo é determinado por relações políticas, relações de força e condições materiais, no qual os segmentos indígenas, entre eles os Baniwa, operam mudanças em: sua cosmologia, suas concepções míticas e estéticas, sua magia, seus ritos, suas bases materiais e línguas, apropriando-se - mas também recriando e reelaborando, de acordo com critérios e paradigmas de suas próprias culturas - dos elementos da cultura dominante. Esse modo de entender descarta uma concepção puramente receptora e inativa das culturas indígenas. A referência a esse processo é feita para destacar a criação de espaços de educação dos Baniwa através da implantação dos colégios salesianos, das escolinhas, de cursos e mesmo das associações indígenas.

O estudo de Weigel e Ramos (1991) sobre os internatos salesianos para os índios do Alto Rio Negro, implantados na região de 1915 a 1953, mostrou que a escola indígena pode ser um espaço ambivalente e contraditório, em que, tanto do ponto de vista do índio quanto do não-índio, efeitos antagônicos podem ser produzidos.

No caso dos internatos, na qualidade de instituição da cultura ocidental imposta às populações indígenas, pode-se afirmar que facilitou a difusão de cer- 
tos elementos dessa cultura (como, por exemplo, a escrita em língua portuguesa), o que contribuiu para o fortalecimento da ideologia modernizante, hegemônica, na sociedade nacional, ao mesmo tempo em que colocava esses elementos ao alcance de membros do grupo indígena, de modo que pudessem transformálos em instrumentos para suas ações. $\mathrm{O}$ estudo mostra que a língua portuguesa aprendida nos internatos foi utilizada, em vários momentos, em suas defesas, denúncias e reivindicações. Desse modo, a escola, como todo espaço socialmente construído, é um espaço em aberto, onde as práticas nele empreendidas produzem efeitos resultantes de um feixe de relações que poderíamos denominar de negociações - entre as forças sociais envolvidas.

Para efeito desta investigação, privilegiei os espaços educativos que se instituem nas escolas das comunidades, no colégio religioso e nas associações Baniwa. Esses espaços vêm sendo povoados por diferentes atores: professores Baniwa e Tukano, católicos e protestantes, religiosos salesianos, padres, missionários protestantes das Novas Tribos do Brasil, funcionários de órgãos públicos, militares, agentes de entidades não-governamentais, e os diversos membros das famílias Baniwa.

Nas interpretações sobre a implantação da educação escolar na região do rio Içana, tem sido enfatizado seu caráter de instrumento de imposição da cultura ocidental, mediando, pela força das idéias e da pedagogia, a destruição da identidade étnica e a assimilação do Baniwa à sociedade nacional, como nas afirmações de Oliveira (1992):

Frente ideológica de expansão, [...] processo de catequização missionária, cuja principal característica foi a [...] inclusão da população indígena no contexto civilizatório regional, através do processo de educação formal nas escolas. (p. 51)

Esse entendimento focaliza o poder político, econômico e simbólico dos agentes promotores da escola, minimiza a atuação e a reação dos próprios indígenas e não considera o movimento que engendra criação/destruição/recriação de significados dentro do espaço escolar. Em contrapartida, é preciso avaliar também a posição da escola na hierarquia das relações que tecem as estruturas sociais e culturais, bem como as transformações que vão se operando nessas relações, redefinindo-se o próprio significado da escola para o povo Baniwa. Em outras palavras, o sentido da escola não tem sido o mesmo, porque as relações vividas pelos Baniwa também se transformaram.

A escola Baniwa, então, configura-se como uma situação de confronto intercultural, na medida em que tem sido espaço de conflitos entre as culturas, os interesses e o poder dos diferentes atores sociais envolvidos. É essa natureza conflituosa que modifica o sentido vertical de imposição atribuído à educação escolar e evidencia seu caráter de possibilidade. As possibilidades existentes são engendradas por conexões e subordinações a condicionamentos mais amplos, como é próprio das relações pedagógicas.

Desse modo, as relações estabelecidas entre os atores para tecer a educação dos Baniwa devem ser entendidas e explicadas no âmbito da história do povo e contextualizadas com estruturas sociais, econômicas e culturais da sociedade capitalista com a qual se estabelecem as relações interculturais, bem como com as estruturas específicas do campo da educação.

Colocou-se, então, como questão central desta pesquisa a análise dos significados e repercussões que a educação - seja nas escolas introduzidas pelos nãoíndios, seja nos espaços educativos criados pelos próprios indígenas - tem produzido na cultura e na vida dos Baniwa do Alto Rio Negro. Investigar essa questão representou compreender e explicar, entre outros aspectos, os diferentes projetos educativos que se configuram na diversidade das práticas educativas, o modo como os processos educativos afirmam a heterogeneidade e a homogeneidade desse povo, os resultados dos processos educativos empreendidos pelos agentes da cultura ocidental, e a multiplicidade de efeitos e repercussões das práticas educativas heterogêneas.

Metodologicamente, a investigação efetivou-se pela articulação da observação participante com a 
análise de âmbitos sociais que extrapolam o campo localizado da pesquisa, além do exame de documentação histórica. A abordagem do povo Baniwa e de suas formas de educação escolar deu-se como apreensão de ações humanas, concebidas, essencialmente, como a expressão de estados de consciência, como o produto de um conjunto de valores e o resultado de variadas motivações - políticas, econômicas, ideológicas, simbólicas e imagéticas.

Foram envolvidos os atores sociais articulados às múltiplas relações que tecem os processos de educação dos Baniwa. Num primeiro nível de abordagem, a ênfase foi dada a indivíduos, com o intuito de apreender a heterogeneidade das formas de inserção, de interesses e de projetos constitutivos das suas ações. Num segundo nível, a ênfase foi dada aos atores sociais em movimento, nas diferentes relações que estabelecem para produzir o campo específico da educação escolar Baniwa. Os critérios do domínio da história e de pertinência na estrutura do campo social específico da educação escolar Baniwa, então, foram usados para identificar os principais atores do drama escolar Baniwa: o avô e a avó da comunidade, os pajés, o professor índio, os pais, as mães e os alunos das escolas Baniwa, os dirigentes das três associações Baniwa e os capitães das comunidades, os religiosos católicos e os missionários evangélicos.

\section{Os diferentes projetos de educação entre os Baniwa}

Examinar a história da educação formal entre os Baniwa revela a existência de projetos de educação diferentes, ligados a diferentes interesses e visões de mundo. Podemos distinguir um projeto articulado por missionários católicos e outro (se é que se pode denominar de projeto de educação), por missionários evangélicos.

O trabalho educacional de maior repercussão foi encetado pelos religiosos salesianos. É no sentido de procurar aprofundar e consolidar entre os indígenas a produção de um estilo de vida e de um imaginário adequados aos interesses dos grupos sociais dominan- tes que o Estado brasileiro acolhe, respalda e apóia a fundação da escola e de um vasto trabalho missionário no Alto Rio Negro, pelos religiosos salesianos, na segunda década do século XX. Por outro lado, a ação missionária foi fundamental para assegurar o domínio do território e a ampliação das fronteiras nacionais, implantando povoados, convencendo os indígenas a habitá-los e desenvolvendo atividades produtivas. Ninguém melhor do que os missionários para ocupar a região do Alto Rio Negro e, com suas ações, contrabalançar as ações dos comerciantes, nem sempre muito patrióticos, e assegurar a permanência dos indígenas que sempre emigraram do país, fugindo das perseguições ou buscando vida melhor.

O ano de 1915 é apontado como a data de fundação do primeiro centro missionário salesiano, no Alto Rio Negro. Dom Pedro Massa, o prefeito apostólico que substituiu Monsenhor Giordano em 1919, denominou esses centros de núcleos de civilização. Construídos em locais estrategicamente escolhidos, pela proximidade das áreas com maior densidade populacional, os centros missionários, imponentes conjuntos de grandes prédios, reuniam escola, internato, oficina, maternidade, ambulatório, hospital, dispensário, igreja, além da residência dos religiosos e até, em alguns casos, estações meteorológicas. Ao todo, até o início da década de 1950, foram instaladas sete grandes sedes de missão.

O empreendimento salesiano no rio Içana, já tardio, só começa em 1953. Está claro que os Baniwa discerniam benefícios que adviriam da ação missionária e, ao mesmo tempo, percebiam que os religiosos também extrairiam lucros dessa empreitada. Havia vontade e empenho dos indígenas na concretização da obra missionária, pois a ação missionária dos salesianos foi vista como mediadora de desenvolvimento, sendo a principal manifestação a escolaridade e o domínio da escrita em português. Vemos assim que razões históricas levaram os Baniwa a responderem positivamente à convocação dos salesianos para a efetivação da empresa missionária.

Mesmo sem dominar a língua portuguesa (muito menos as línguas indígenas), irmãos e irmãs 
salesianos vieram para efetivar com os indígenas o projeto educacional de Dom Bosco: constituir o bom cristão e o bom cidadão. Para isso, instituíram em seus asylos e escolas um sistema educacional (baseado naquele desenvolvido em Turim para os filhos de lavradores), ministrando o curso primário (até a $5^{\text {a }}$ série), o ensino religioso e a formação para o trabalho. Dependendo da oficina existente na Missão, os jovens índios poderiam desenvolver atividades ligadas à carpintaria, marcenaria, olearia e alfaiataria, para meninos; e bordado, artesanato e corte e costura, para meninas. Além disso, todos os alunos e alunas envolviam-se com agricultura, trabalhando nas roças da Missão, na faina necessária à produção agrícola destinada ao consumo. As alunas índias também eram responsáveis pelo empreendimento das atividades de cozinha, limpeza e lavagem de roupa do alunado.

Além de utilizar o braço índio, os missionários tinham para os índios um projeto civilizador. De acordo com seu modelo de civilização, condenavam a vida tribal, a habitação em malocas e a economia de autosustentação. Nesse sentido, não apenas atraíam os indígenas para a circunvizinhança das Missões, como também trataram de criar aldeias nas proximidades, como fizeram os missionários do passado.

Como educadores experientes, os salesianos apostavam na formação das crianças e jovens, por estarem convencidos de que adultos e idosos "já estavam viciados" e não responderiam positivamente aos seus ensinamentos civilizatórios, conforme orientação do mestre Dom Bosco.

O processo para formar o bom cidadão nesse contexto rionegrino incluía a imposição da língua portuguesa. Mesmo que alguns padres tivessem que aprender a língua indígena da região onde atuavam, para serem compreendidos, na escola estudava-se exclusivamente o idioma nacional, sendo ele de uso obrigatório nas comunicações dentro do internato. Além disso, a língua configurava-se como uma instituição fundamental das identidades tribais, sendo, por isso, incompatível com o modelo de cidadão que era objetivo formar.
$\mathrm{Na}$ área dos Baniwa, como vimos anteriormente, o internato salesiano somente foi implantado no início da década de 1950, período pós-guerra, quando a região do Içana vivia uma fase de grande conversão ao protestantismo. Se, por um lado, foram as relações com os Baniwa que levaram ao desaparecimento dos internatos e ao definhamento do Centro Missionário, por outro, podemos distinguir, a partir da década de 1970, condições de ordem estrutural, ligadas ao reordenamento econômico mundial, às transformações ideológicas dentro da própria Igreja católica e à crescente politização de frações sociais oprimidas, favorecida pela aliança de setores intelectualizados da sociedade civil nacional e internacional.

Em meados da década de 1970, a escola salesiana do Içana tornou-se mista, passando ao controle total das Filhas de Maria Auxiliadora, as irmãs salesianas. Em 1977, a resolução $n^{\circ} 114$ do Conselho Estadual de Educação, publicada no Diário Oficial de 27 de janeiro, aprova o regimento escolar da Unidade Educacional Dom Pedro Massa, da qual faz parte a préescola e a escola de primeiro grau Nossa Senhora de Assunção, no rio Içana, funcionando sob o controle e a fiscalização da Secretaria Estadual de Educação do Estado do Amazonas. Encerrou-se, então, a fase dos asylos e escolas profissionalizantes. Restaram daquela época apenas os grandes prédios.

Com a extinção dos internatos, os missionários salesianos foram levados a pensar em outra estratégia para a educação escolar que consideravam necessário ministrar às crianças índias. Desse modo, na década de 1970, Irmã Teresa e Padre Carlos criaram escolinhas nas várias comunidades católicas, destinadas à alfabetização em língua portuguesa e ensino das primeiras contas. Semelhantes às casas de moradia das famílias, essas antigas escolas são construídas de taipa, cobertas de palha caranã e possuem dois ou três cômodos. Para o funcionamento das escolas, Irmã Teresa contou com os ex-alunos do Colégio de Assunção, que, tendo concluído a quinta série, passaram a atuar como professores.

Na década de 1980, foi instituído o órgão municipal de educação de São Gabriel da Cachoeira, um 
setor da prefeitura com poderes e responsabilidades relativos à organização e administração do sistema escolar do município. As escolas das comunidades indígenas oficializaram-se, passando para a jurisdição municipal, mesmo que as irmãs salesianas continuassem a supervisioná-las até o início dos anos 1990. Nelas são ministradas as quatro primeiras séries do ensino fundamental, em classe multisseriada.

No final da década de 1940, o protestantismo instalou-se no Alto Rio Negro, principalmente na área dos Baniwa do rio Içana e seu maior afluente, o rio Aiari. Segundo distingue Wright (1981), em 1976 havia três missões protestantes no rio Içana e somente duas no rio Uaupés. A pioneira foi a americana Sofia Müller, missionária fundamentalista da New Tribes Mission.

O processo de conversão dos índios, para os protestantes da New Tribes Mission, exigia a mediação de práticas pedagógicas de ensino de leitura em língua indígena. O objetivo precípuo era de que pudessem ler a Bíblia, cuja tradução para o idioma nativo havia sido feita pelos próprios missionários, e, desse modo, salvarem suas almas. Para isso, aulas foram improvisadas, no sentido de viabilizar a alfabetização. De acordo com os próprios relatos de Sofia Müller (1952), o ensino se processava debaixo das árvores, nas casas, nas canoas, onde fosse possível. Ficou também evidente que Sofia não pretendia escolarizar os índios, mas tão somente fazer os velhos decodificarem a escrita, a fim de poderem ler a Bíblia para os demais. Além da leitura e escrita na língua, o ensino visava também preparar os mais velhos para ocuparem os cargos de ancião, diácono e pastor. Estes iriam assegurar a preservação da crença, dando continuidade à realização dos rituais evangélicos. A escola não fazia parte do projeto evangélico.

Depois de Sofia Müller, os Baniwa lembram-se que um pastor americano veio morar no rio Içana: “e depois foi Henrique que fez casa em Seringa-rupitá, na boca do Cuiari. [...] Henrique convidava pessoal do rio para ensinar na casa dele", conta o avô dzawinai, da comunidade Arapaso, rio Içana. Pastor Henrique, colaborador do Summer Institute of Linguistic (SIL), entidade americana de igrejas protestantes, não apenas ensinou os velhos a ler e escrever Baniwa, mas também viabilizou a elaboração de duas cartilhas e dois livros de exercícios para serem usados no processo de alfabetização da língua indígena. Foi a primeira proposta de grafia do Baniwa falado no Brasil, que é diferente do que é falado na Colômbia.

Na comunidade de Jandu-cachoeira funcionava, desde 1970, uma escola bíblica, fundada pelo pastor Jaime, missionário americano que ficou quase vinte anos evangelizando no rio Içana. A escola "regular", que significava escolaridade de $1^{\mathrm{a}}$ a $4^{\mathrm{a}}$ série, só foi criada em 1975. Para trabalhar nessa escola vieram mais duas missionárias, uma americana e uma paulista. No início da década de 1980, alguns alunos já haviam concluído a $4^{\mathrm{a}}$ série na escola de Jandu, e então foram organizadas escolas em outras duas comunidades protestantes, onde esses ex-alunos foram lecionar.

A escola de Jandu fechou em 1988. Todas as escolinhas organizadas pelos protestantes desde que o Órgão Municipal de Educação foi criado, em 1983, passaram para a jurisdição da Prefeitura de São Gabriel. Gradativamente, os missionários protestantes foram se desobrigando da supervisão das escolas fundadas por sua iniciativa. Atualmente, eles não têm mais nenhuma atividade ligada à escolarização regular. "A escola é dever do Estado", diz o pastor que mora no rio Içana.

Fica evidente que a estratégia dos missionários protestantes, para divulgação de suas idéias evangelizadoras e cristianização dos Baniwa, diferia substancialmente da católica. Enquanto os salesianos seguiam a orientação de Dom Bosco, que dizia "ocupai-vos primeiro das crianças e ganhareis depois os adultos", e investiam no projeto educativo desenvolvido em seus internatos e escolinhas, a estratégia dos protestantes era bem diferente. Consistia em, usando a hierarquia da sociedade indígena, conquistar primeiro os mais velhos, os que tinham a autoridade e o respeito dos demais, os que eram ouvidos e, por isso, tinham influência sobre a formação das novas gerações. Mas o fato de não terem desenvolvido a educa- 
ção escolar e de terem ensinado a ler na língua indígena, em detrimento do português, é avaliado hoje, pela maioria dos velhos, chefes e professores Baniwa, católicos, como um prejuízo para o povo.

Os católicos consideram que o protestantismo foi um atraso para os Baniwa. Dos velhos e chefes protestantes com quem conversei, certamente nenhum se considera atrasado. Essa é uma idéia muito trabalhada pelos salesianos: progredir, "ir pra frente", através da escolarização. Porém, alguns têm um posicionamento favorável em relação à necessidade de mais escolarização para suas crianças. Se, por um lado, as escolinhas improvisadas de Sofia Müller ensinavam a escrita da língua indígena e isso pode representar uma forma de valorização da cultura, por outro lado, estão ligadas apenas à leitura da Bíblia, significando uma restrição e uma imposição cultural, tal qual a escola dos missionários católicos.

\section{Sentidos e repercussões da educação escolar}

O sentido da escola para os Baniwa transformouse à medida que foram se transformando as relações vividas com os brancos, as condições históricas dessas relações e os interesses Baniwa em jogo. No curso do processo cotidiano das experiências sociais e históricas, as idéias Baniwa sobre a escola assumem um caráter pragmático, uma vez que estão ligadas a intenções e finalidades concretas.

É possível distinguir três momentos na história Baniwa, marcados por interesses distintos quanto à escolaridade. O primeiro desses momentos corresponderia ao período de implantação e funcionamento do internato salesiano, transcorrido ao longo da década de 1950. O segundo seria relativo à fase de implantação das escolinhas nas comunidades, na década de 1970. Um outro seria perceptível a partir da segunda metade da década de 1980, quando se consolida a educação escolar e começa a aumentar o número de escolas na região do Içana.

Na década de 1950, os chefes Baniwa permitem que seus filhos ingressem no colégio salesiano de Assunção do Içana. Longe de ser simplesmente fruto de uma coação ou resultar de uma imposição absoluta dos salesianos sobre os Baniwa (entendimento que, metodologicamente, seria um reducionismo, pois deixaria de tratar os Baniwa como atores sociais efetivos), a permissão para o ingresso dos jovens no colégio de Assunção enquadra-se mais como uma estratégia Baniwa diante de exigências e desafios apresentados pelo processo histórico. Os Baniwa procuravam meios de adaptarem-se à situação irreversível de dependência em relação aos brancos, visto que eram alvo da violência de muitos deles (comerciantes, seringalistas, militares, entre outros).

A multiplicação das escolinhas pelas comunidades, nos anos de 1970, opera a consolidação da escola como um espaço em que seria possível aos Baniwa tomarem posse de códigos e linguagens, tão necessários para as relações com os brancos. Segundo depoimentos, através disso seria possível conhecer a vida dos brancos e, então, saber como lidar com eles; poderiam falar português, isto é, comunicar-se com os brancos e não deixar-se confundir por eles. O domínio desses elementos simbólicos significava não só um instrumento de defesa, mas também de autoconfiança e de auto-estima, na medida em que podiam colocar-se em pé de igualdade com os brancos, transitando nos mesmos campos simbólicos e manipulando os mesmos códigos.

Na segunda metade da década de 1980, criou-se a primeira associação na região do Içana, a Associação das Comunidades Indígenas do Rio Içana (ACIRI). Gradativamente, alguns Baniwa começaram a interiorizar o submundo ${ }^{1}$ das organizações políticas e, por conseguinte, a aprender a linguagem e os conhecimentos do subuniverso de significados próprios da esfera política.

A "entrada" das associações indígenas no submundo, habitando o subuniverso da ação política, possibi-

\footnotetext{
${ }^{1} \mathrm{O}$ conceito de submundo é de Berger e Luckmann (1985,
} p. 184-185), consistindo em campos institucionais específicos, constituídos de conhecimentos, vocabulário, regras de comportamento, rotinas e padrões estéticos próprios. 
litou, então, aos Baniwa encarregados de dirigi-las, interiorizar e objetivar as condutas institucionalizadas: reuniões políticas (assembléias, encontros, conferências) e técnicas (discussão de orçamentos e projetos), além dos rituais burocráticos (relatórios, ofícios, atas, projetos, prestação de contas).

Não se pode desconsiderar o fato de que, concretamente, os Baniwa estão vivendo relações sociais mais amplas, estão inseridos na estrutura de classes da sociedade brasileira e participam, embora de modo desigual, dos processos de produção, distribuição e consumo dos bens simbólicos e materiais. Fazem parte, portanto, da sociedade capitalista em que vivemos.

Aqui, um outro ponto que se impõe e merece ser focalizado é a questão da identidade sociocultural. Permanecem em curso movimentos, processados pela dinâmica das relações travadas no contexto das estruturas da sociedade nacional, forjando a reconstrução de uma identidade coletiva que se fortalece como referência para os subgrupos Hohodene, Dzawinai ou Uaripere-dakenai, sejam católicos ou protestantes: é a identidade Baniwa. Essa identidade vem, gradativamente, ganhando nova conformidade, consistência e validade à medida que o povo se defronta com problemas e pressões criados pelas estruturas sociais e culturais da sociedade de classes, no processo de integração à nação brasileira.

Se antes essa autodesignação genérica não existia entre os índios Baniwa do Brasil, agora já se pode verificar no discurso dos dirigentes das associações, dos professores e dos capitães a referência ao povo Baniwa: expressões como "artesanato característico dos Baniwa", "professores Baniwa", "pensadores Baniwa" e "povo Baniwa" estão sendo usadas no Informativo e em outros documentos da Associação das Organizações Indígenas da Bacia do Içana (OIBI). Nesse sentido, quando o interesse pela escola se manifesta com base no argumento da promoção do "desenvolvimento do povo Baniwa", penso que isso significa estar o trabalho da escola articulado a processos mais complexos de afirmação e constituição dessa identidade Baniwa, no âmbito da sociedade nacional. Tais processos compreendem e implicam, ao mesmo tempo, a formulação de utopias e de projetos políticos coletivos, delineados no quadro sociopolítico da nação brasileira.

Quando focalizada no sentido de produção e manutenção da identidade Baniwa, a educação escolar configura-se como um instrumento instaurador de unidade, isto é, funciona como mediadora de elementos homogeneizadores e centralizadores de energia que contribuem para manter o povo unido.

Simultaneamente, a educação escolar também pode produzir resultados que têm repercussões heterogeneizadoras e descentralizadoras, potencialmente criadoras de divisões internas do grupo. A escola determina o acesso e a distribuição de bens culturais muito valorizados, em virtude dos condicionantes que delimitam as relações vividas pelos Baniwa nas formas atuais de integração social. Bourdieu (1992) pode iluminar o entendimento dessa dimensão disjuntora da escola, quando afirma que

A escola não cumpre apenas a função de consagrar a "distinção" - no sentido duplo do termo - das classes cultivadas. A cultura que ela transmite separa os que a recebem do restante da sociedade mediante um conjunto de diferenças sistemáticas: aqueles que possuem como "cultura" (no sentido dos etnólogos) a cultura erudita veiculada pela escola dispõem de um sistema de categorias de percepção, de linguagem, de pensamento e de apreciação que os distingue daqueles que só tiveram acesso à aprendizagem veiculada pelas obrigações de um ofício ou a que lhes foi transmitida pelos contatos sociais com seus semelhantes. (p. 221)

Assim, o domínio de diferentes formas de linguagem, de determinados hábitos e atitudes, e a posse de conhecimentos dos subuniversos de significação próprios do mundo dos brancos transformam-se em capital simbólico acumulado por aqueles Baniwa que passaram pela escola - os jovens, na maioria católicos. É nesse sentido que a escola produz resultados que apresentam repercussões heterogenizadoras. À proporção que os Baniwa são enredados no tecido social mais amplo, aqueles que passaram pela esco- 
la encontram-se em posição mais vantajosa, pela posse de bens culturais valiosos tanto do ponto de vista do reconhecimento social, quanto do ponto de vista prático.

Desse modo, as crianças Baniwa, durante sua primeira socialização, entre outras normas e valores institucionais, apreendem os significados da obediência e respeito aos pais, avós e tios, estabelecidos por normas Baniwa tradicionais. Essas normas constituem-se em valores e convicções morais na orientação das ações e regulamentação do consenso entre os membros da família Baniwa. Nas relações geracionais, dentro da hierarquia familiar, as diferenças produzidas pela educação escolar, no que concerne a criar um adicional de poder simbólico para os mais jovens, estão sendo superadas por essas normas que orientam as relações de parentesco.

Nas relações estabelecidas entre católicos e protestantes, os conflitos são mais evidentes, porque também estão associados a divisões e disputas tradicionais entre os grupos. Em razão da antiga aliança com os salesianos, as famílias católicas têm maior número de filhos escolarizados. A posse desse valioso bem cultural - a instrução escolar - apresenta-se como fator intensificador da diferença e divisão entre os grupos, que os católicos escolarizados externam ao evocar o atraso trazido pelo protestantismo.

Entre os Baniwa protestantes, por terem abandonado essas tradições, de fato as gerações mais novas parecem desconhecer as antigas instituições da sua cultura, como os mitos de origem, os rituais de iniciação, os rituais xamanísticos e as festas do dabakuri e pudare. ${ }^{2}$ É bem verdade que os jovens protestantes escolarizados, que estão à frente da associação, vêm buscando transformar esse modo de pensar e agir dos Baniwa protestantes, por compreenderem a importância desses elementos culturais para o movimento político de afirmação sociopolítica do

${ }^{2}$ Dabakuri e Pudare eram cerimoniais de troca, realizados sempre que houvesse um excedente de peixe, frutas e caça, em que eram convidados os parentes de outras comunidades. povo Baniwa. Querem introduzir as histórias míticas no currículo da escola. Mas referem-se às instituições tradicionais Baniwa como uma coisa já morta, existente num passado longínquo.

\section{À guisa de conclusão}

Todas as formações sociais têm a percepção da possibilidade do seu desaparecimento, identificado com o caos e a desordem. Por isso, principalmente nas conjunturas de crise, suas forças se colocam no sentido de impulsionar modos de recriação e renovação da sociedade. Para os Baniwa, penso que o medo da entropia e a percepção da vulnerabilidade da estrutura tradicional, diante da força dos dinamismos "de fora" (expressão de Balandier, 1969), compeliram-nos a criar mecanismos capazes de restaurar a unidade social, embora em outras bases impostas pelo processo histórico.

Não cabendo mais os rituais e ensinamentos tradicionais, a escolaridade assumiu essa função de restauração da sociedade, pois o estado de plenitude e de cidadania (no sentido de tornar-se membro daquela sociedade) a que ela permite acesso está sendo percebido como condição de vida e de ordem da sociedade. A educação escolar é renascimento.

Nesse sentido, a escola representa tanto a luta pela sobrevivência Baniwa, contribuindo para a construção de uma nova identidade, quanto a esperança de felicidade no futuro. Os Baniwa buscam na escola meios - linguagens, conhecimentos e códigos - que contribuam para a produção de um ajustamento e uma organização social modificada, para melhor se adaptarem às novas condições históricas.

Essas novas condições históricas impõem um fato inquestionável: os Baniwa existem num tecido social mais amplo, a sociedade brasileira. O empreendimento da luta pela identidade sociocultural significa construir uma visibilidade da sua presença no conjunto desse tecido social, de modo a garantir um espaço e um tempo: "os pajés mesmo vêem isso... vão vir muitos brancos, vão encher aqui... muita coisa vai mudar ainda..." (índio Baniwa). 


\section{VALÉRIA AUGUSTA CERQUEIRA DE MEDEIROS}

WEIGEL, doutora em antropologia pela Pontifícia Universidade Católica de São Paulo, é professora do Programa de Pós-Graduação em Educação da Universidade Federal do Amazonas. Entre outros textos sobre educação escolar indígena, publicou Escolas de branco em malokas de índio (EDUA, 2000). Coordena a pesquisa Identidades amazônicas, meio ambiente e educação, estudo da mediação da escola nas relações homem/meio, com povos indígenas e grupos caboclos da região.E-mail: valeriaweigel@ fua.br

\section{Referências bibliográficas}

BALANDIER, Georges, (1969). Antropologia política. São Paulo: EDUSP/ DIFEL. Tradução de Octávio Mendes Cajado.

BERGER, Peter, LUCKMANN, Thomas, (1985). A construção da realidade social: tratado de sociologia do conhecimento. Petrópolis: Vozes. Tradução de Floriano de Souza Fernandes. BOURDIEU, Pierre, (1992). A economia das trocas simbólicas. $3^{a}$ ed. São Paulo: Perspectiva. Tradução de Sérgio Miceli, Sílvia de Almeida Prado e Wilson Campos Vieira.

MÜLLER, Sofia, (1952). Beyond civilization. Woodworth: Brown Gold Publication.
OLIVEIRA, Ana Gita, (1981). Índios e brancos no Alto Rio Negro: uma situação de contato dos Tariana. Dissertação de Mestrado em Antropologia. Universidade de Brasília. , (1992). O mundo transformado: um estudo da "cultura de fronteira" no Alto Rio Negro. Tese de doutorado em antropologia. Universidade de Brasília.

RIBEIRO, Darci, (1970). Os índios e a civilização. Rio de Janeiro: Civilização Brasileira.

WEIGEL, Valéria, RAMOS, Ademir, (1991). O processo educativo dos internatos para os índios do Alto Rio Negro. Bulletin of the International Committe on Urgent Anthropological and Ethnological Research, p. 32-33.

WRIGHT, Robin, (1981). History and religion of the Baniwa peoples of the upper Rio Negro Valley. Tese de doutorado em filosofia. Stanford University.

, (1994). Quando as missões vieram. 19 $9^{\mathrm{a}}$ Reunião da Associação Brasileira de Antropologia (ABA), Niterói. Comunicação, p. 1-15, (mimeo).

Recebido em setembro de 2002 Aprovado em novembro de 2002 